Supporting information

\title{
Evaluation of data analysis platforms and compatibility with MALDI-TOF imaging mass spectrometry datasets.
}

Gordon T. Luu ${ }^{1, \Xi}$, Alanna R. Condren ${ }^{1, \Xi}$, Lisa Juliane Kahl², Lars E.P. Detrich², and Laura M. Sanchez ${ }^{1 *}$

1. Department of Pharmaceutical Sciences, University of Illinois at Chicago, Chicago, IL 60612

2. Department of Biological Sciences, Columbia University, New York, NY 10027

$\Xi \quad$ Denotes equal contribution

* Corresponding Author

optimizeSSCParameters: Optimization of spatialShrunkenCentroids Parameters......... S3

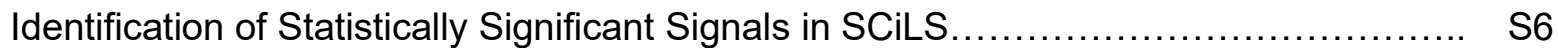

Identification of Statistically Significant Signals in Cardinal......................... S6

Equation S1: Number of Unique Predicted Segments Weight $\ldots \ldots \ldots \ldots \ldots \ldots \ldots \ldots \ldots \ldots$ S 8

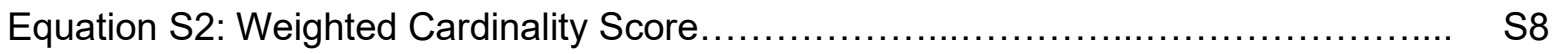

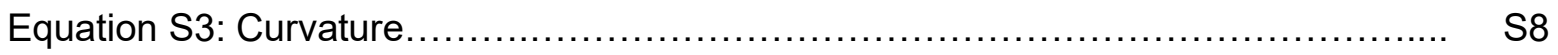

Figure S1: Segmentation map SCiLS vs Cardinal of IMS Replicate $2 \ldots \ldots \ldots \ldots \ldots \ldots \ldots$ S9

Figure S2: Segmentation map SCiLS vs Cardinal of IMS Replicate $3 \ldots \ldots \ldots \ldots \ldots \ldots \ldots$ S10

Figure S3: Segmentation map SCiLS vs Cardinal of IMS Replicate $4 \ldots \ldots \ldots \ldots \ldots \ldots \ldots \ldots$ S11

Figure S4: Segmentation map SCiLS vs Cardinal of IMS Replicate $5 \ldots \ldots \ldots \ldots \ldots \ldots \ldots$ S12

Figure S5: Optical image of ring formations of PA14 biofilms $\ldots \ldots \ldots \ldots \ldots \ldots \ldots \ldots \ldots . \quad \mathrm{S} 13$

Figure S6: Number of Predicted Segments vs shrinkage parameter (s)..................... S14

Figure S7: Weighted Cardinality Score vs shrinkage parameter (s).......................... S15

Figure S8: Effect of spatial neighborhood radius ( $r$ ) on unsupervised segmentation...... S16

Table S1: Publications that have used Cardinal.................................... S17

Table S2: Preprocessing parameters for each dataset in Cardinal ................... S18

Table S3: SpatialShrunkenCentroid parameters for unsupervised segmentation......... S18 


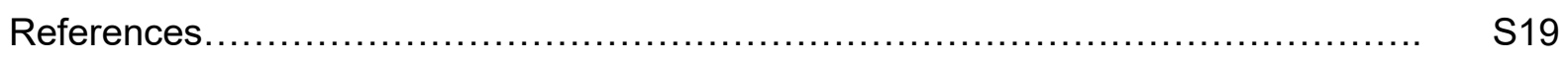


optimizeSSCParams: Optimization of spatialShrunkenCentroids Parameters

Unsupervised segmentation of IMS data sets using the spatial shrunken centroids (SSC) algorithm requires users to initialize the spatial neighborhood radius $(r)$, number starting of segments (k), and shrinkage parameter (s) by providing a single set or vector of sets of $r, k$, and s. It is up to the user to initially provide values for each parameter, and Cardinal will run each permutation of the sets of parameters to generate a model for each set. But once these models are generated, manual analysis is required to determine which model (and its set of parameters) is ideal, meaning segments representing the true biology of the sample are kept while dropping any extraneous segments/artifacts. Therefore, we have developed a heuristic algorithm to help optimize the set of parameters chosen for segmentation with SSC by first optimizing s before optimizing $r$ and $\mathrm{k}$. The algorithm has been implemented in our cardinalscripts package as the function optimizeSSCParams.

Bemis et al. described the optimal value for s as the value in which (1) the predicted segments from different numbers of starting segments $(k)$ were comparable and $(2)$ the predicted number of segments stabilizes (stops decreasing) as $s$ increases. ${ }^{1}$ The predicted number of segments for each pair of $r$ and $k$ vs $s$ were plotted as is and henceforth referred to as a line (Figure S6). To meet these two criteria, weight values for each unique data point for a given value s (Figure S6) were calculated using Equation 1 to generate a vector of weight values for that value of $\mathrm{s}$, and a weighted cardinality score incorporating this vector of weight values was then calculated using Equation S2. This approach was chosen because as $\mathbf{S}$ increases, its cardinality should decrease due to different lines producing the same number of predicted segments (criterion 1). The weight value obtained from Equation S1 was used to prevent outliers from lines where the initial $\mathrm{k}$ parameter was too low from artificially increasing cardinality. A new plot was then generated for weighted cardinality score vs s (Figure S7). The Kneedle algorithm was used to identify the "knee", or point where the data points stabilize (criterion 2), to yield the optimal value for s (Figure S7A). ${ }^{2}$ In the event that the weighted 
cardinality scores are equal for sequential values of s, the Kneedle algorithm incorrectly predicts the knee to be located at the beginning of the plateau. This plateau is the result of many lines having the predicted number of classes equal to $\mathrm{k}$. Therefore, values contributing to the plateau effect are removed to accurately determine the optimal value for s (Figure S7B).

Unlike the s parameter, $r$ and $k$ are more qualitative, flexible parameters. The $r$ parameter should be large enough that individual or small chunks of pixels will not be grouped into small segments but small enough that the number of predicted segments is not too small (Figure S8). The k parameter should be large enough to allow for the expected amount of segments to appear after segmentation, which may require a priori knowledge. Therefore, it is important that the range of values for $\mathrm{k}$ is appropriate for the biological sample in question when first initializing this parameter. Since no quantitative criteria have been specified, the above guidelines were used to optimize $r$ and $k$. Upon manual inspection, the optimal values for each line appeared to be those in which (1) the line began to stabilize when s was equal to the optimal value for s found previously, (2) had a downward slope that was large enough, and (3) the curvature where s was equal to the optimal value for s was large. Therefore, for each line, the Kneedle algorithm was used to find the knee for each line. If the knee was not equal to the optimal value for s previously found, the line was determined to be sub-optimal and was removed from consideration (criterion 1). In the event that no lines were present where the knee was equal to the optimal value for $\mathrm{s}$, the optimal value for s was increased incrementally until lines where the s value was equal to the knee were found. Lines were then fitted to an exponential curve which was used to calculate the slope of the line. The curvature of the line at the knee was calculated using Equation S3. Both slope and curvature values were multiplied by 100. Finally, a score was calculated for each line by multiplying the slope by the curvature (criteria $2 \& 3$ ). The line with the highest score was chosen as the optimal $r$ and $k$ values. 
Identification of Statistically Significant Signals in SCiLS

To identify significant changes in features between conditions, SCiLS measures the receiver operating characteristic (ROC) to univariately discriminate $\mathrm{m} / \mathrm{z}$ values from two user defined groups. The area under the ROC curve (AUC) is measured and compared between the two groups and a numerical value is assigned. A perfect discrimination of an $m / z$ value between the two groups yields a 0 or 1 . The closer the $A \cup C$ is to 0.5 , the more similar the intensity of an $\mathrm{m} / \mathrm{z}$ value is in both groups. Using the AUC, SCiLS calculates $p$-values to generate a list of discriminate $\mathrm{m} / \mathrm{z}$ values that have significant changes in intensity between the two user defined groups $(p<0.05)$.

Identification of Statistically Significant Signals in Cardinal

The meansTest function in Cardinal can be used to identify statistically significant features between conditions by fitting a linear mixed model. It calculates a likelihood ratio (LR) which appropriates the likelihood of a feature being differentially expressed between the two or more conditions. Each LR is also accompanied by a p-value and false discovery rate. It should be noted that use of meansTest requires at minimum three replicates for statistically significant results whereas SCiLS does not have a minimum replicate requirement. Additionally, Cardinal's meansTest generates a single feature list representative of all replicates analyzed, while SCiLS generates features lists for each individual data set.

The segmentationTest function in Cardinal relies on segmentation models generated by the spatial-Dirichlet Gaussian mixture model (DGMM) algorithm using the spatialDGMM function. Spatial-DGMM was designed to be a more sensitive method to identify statistically significant features by capturing within-sample heterogeneity. It segments ion images for each feature in the data set individually. The segmentationTest function can then use these segmentation models to determine if statistically up or down-regulated features are present between conditions. Similarly to meansTest, an LR accompanied by a p-value and false discovery rate are then calculated using the segmentation model for each feature. The 
segmentationTest function also requires at minimum three replicates and generates a single feature list as its output.

Unlike in SCiLS, LR values do not indicate whether a feature is up or down-regulated, only that there is a difference in expression between conditions. Therefore, features in Supplemental File 1 identified by Cardinal may have duplicates in the "upregulated" and "downregulated" columns. Additionally, LR values are relative. The absolute value of an LR from one analysis may not be translatable to another. Manual analysis of ion images is required to determine whether these features are up or down-regulated. 
Equation S1: Calculation of weight values for each unique data point (number of predicted segments) for each value of s.

weight $=$ frequency of each unique data point for that s value / cardinality for that s value

Equation S2: Calculation of weighted cardinality score to optimize the shrinkage parameter (s) parameter.

weighted cardinality score $=$ number of unique data points / max weight for that s value

Equation S3: Calculation of the curvature of a line at the point where $x$ is equal to the optimal value of $\mathrm{s}$.

curvature $=\left|y^{\prime \prime}(x)\right| /\left(1+\left(y^{\prime}\right)^{2}\right)^{3 / 2}$ 
Figure S1: Segmentation map SCiLS vs Cardinal of IMS replicate 2. (A) Optical image of WT PA14 IMS plate. (B) Segmentation in SCiLS. (C) Segmentation in Cardinal using SSC with optimal parameters.

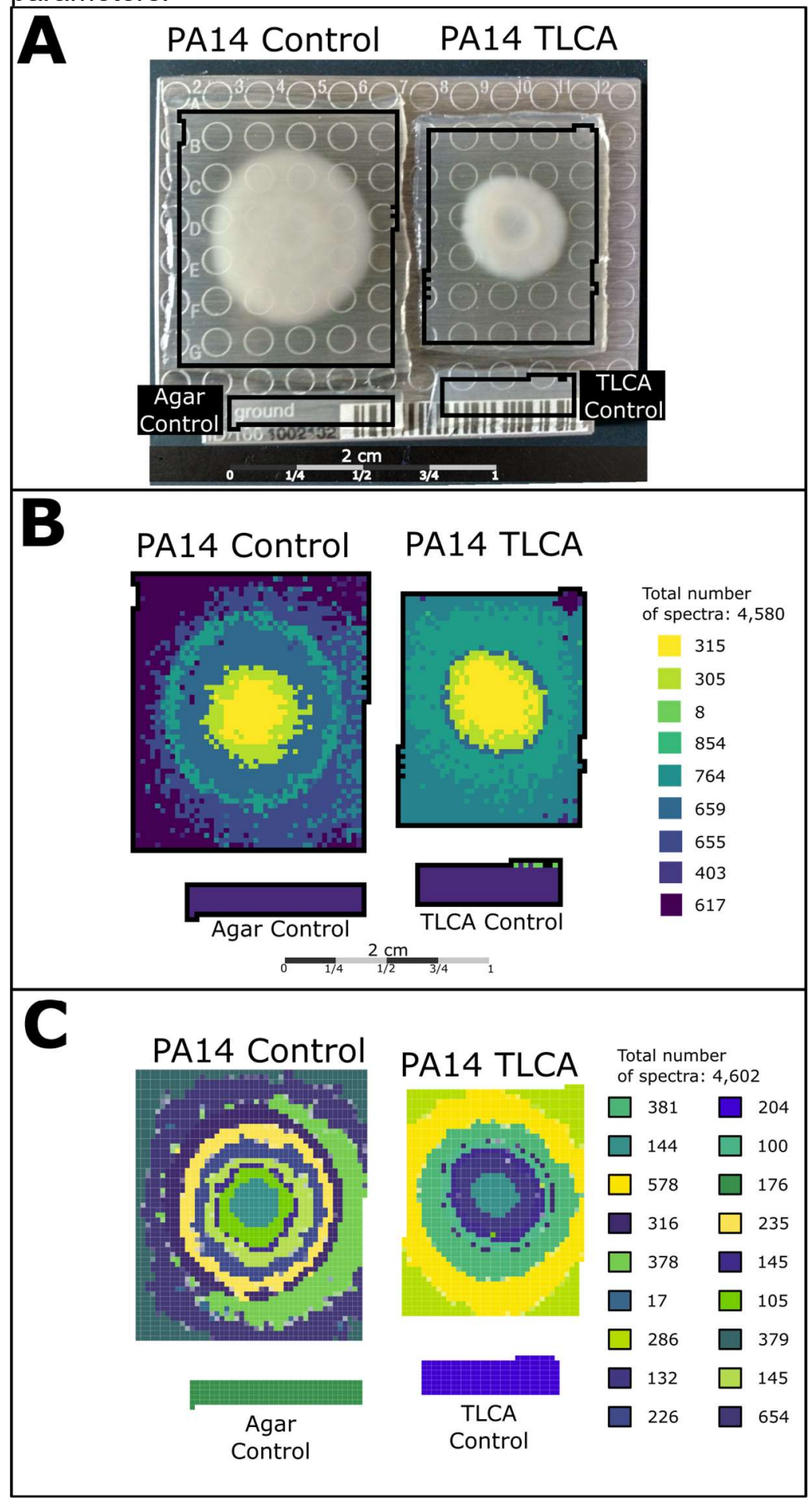


Figure S2: Segmentation map SCiLS vs Cardinal of IMS replicate 3. (A) Optical image of WT PA14 IMS plate. (B) Segmentation in SCiLS. (C) Segmentation in Cardinal using SSC with optimal parameters. The total number of spectra denoted in the figure includes spectra specific to a matrix spot which is not shown.

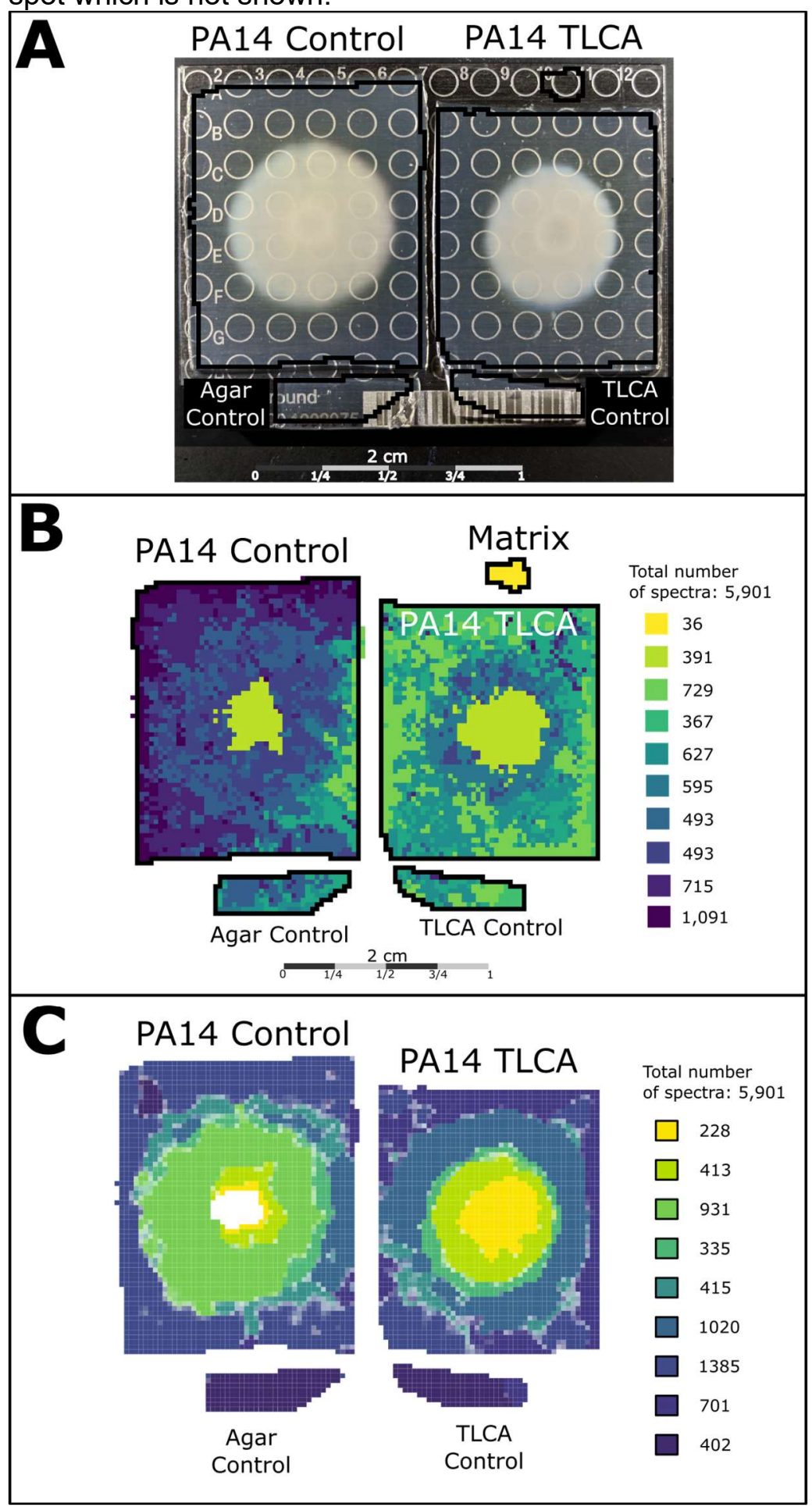


Figure S3: Segmentation map SCiLS vs Cardinal of IMS replicate 4 (raster size: $200 \mu \mathrm{m}$ ). (A) Optical image of WT PA14 IMS plate. (B) Segmentation in SCiLS. (C) Segmentation in Cardinal using SSC with optimal parameters.

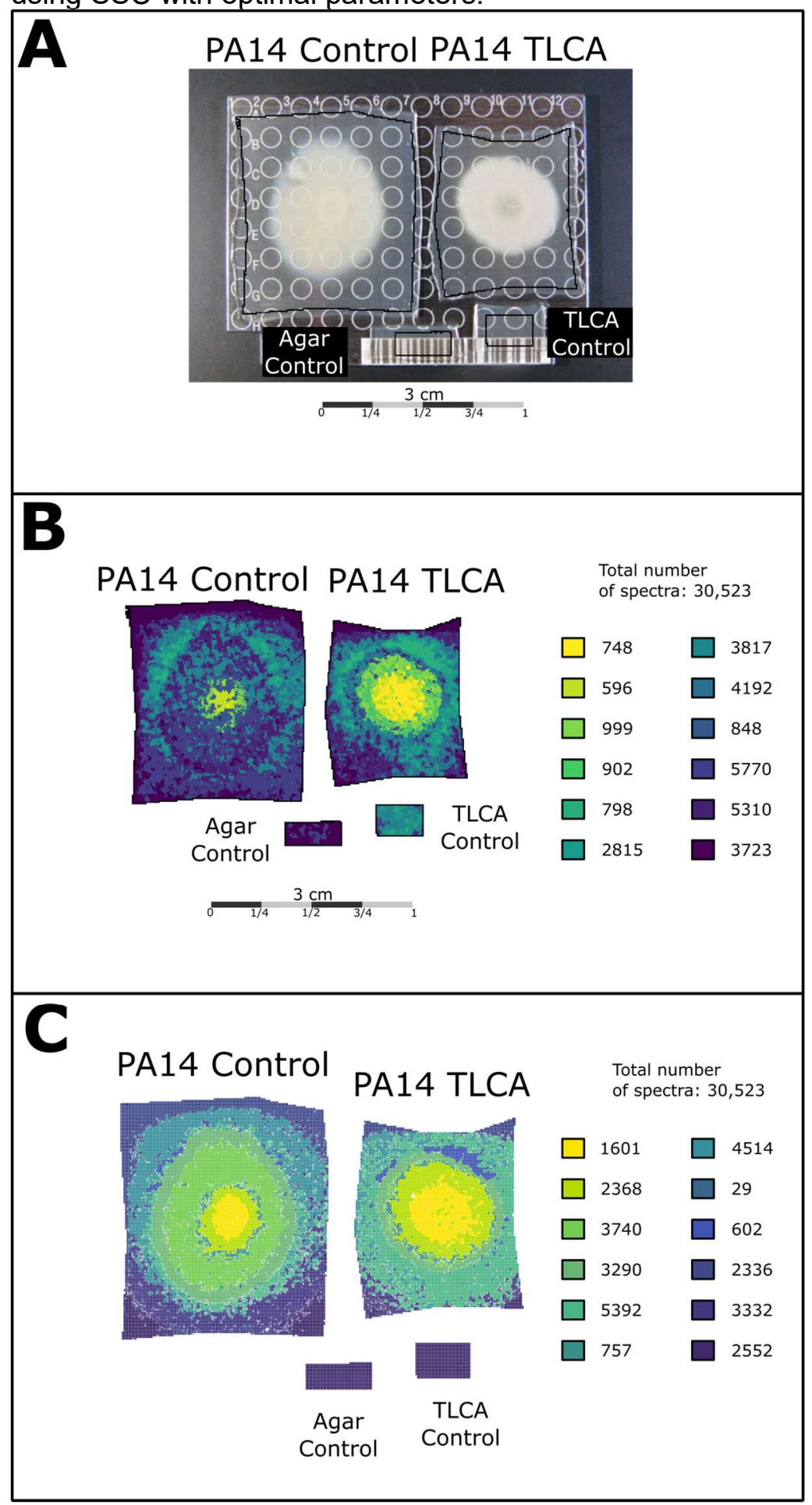


Figure S4: Segmentation map SCiLS vs Cardinal of IMS replicate 5 (partial PA14 control sample). (A) Optical image of WT PA14 IMS plate. (B) Segmentation in SCiLS. (C) Segmentation in Cardinal using SSC with optimal parameters.

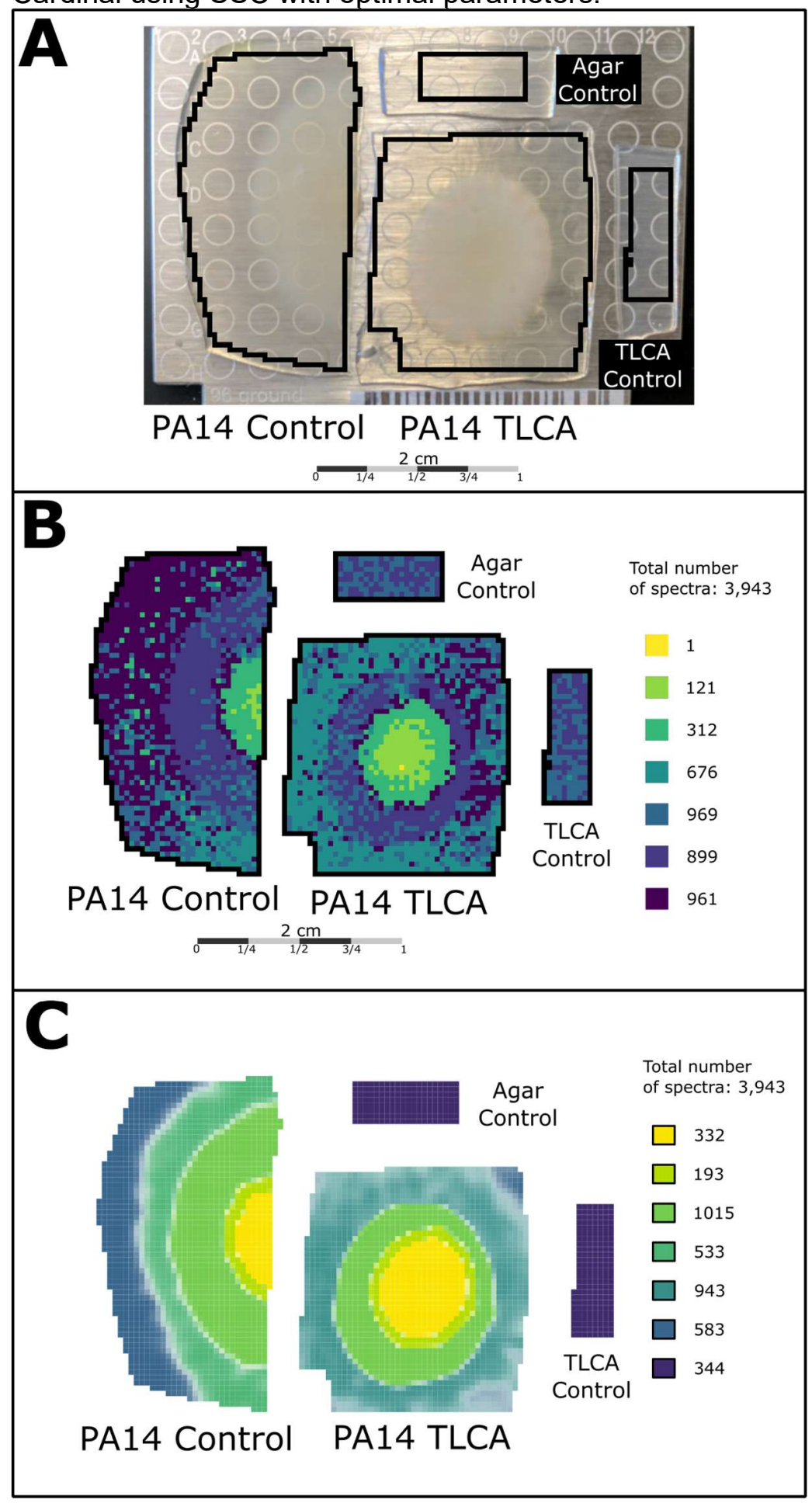


Figure S5: Optical images of four-day-old PA14 biofilms grown with exposure to constant white light or in constant darkness.

\section{constant light}

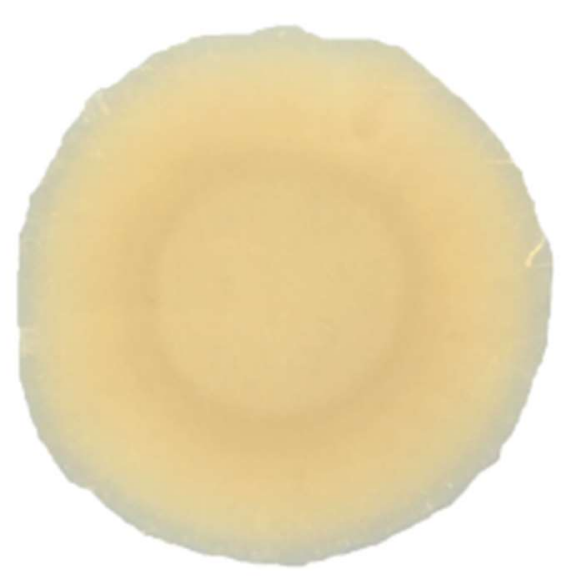

\section{constant dark}

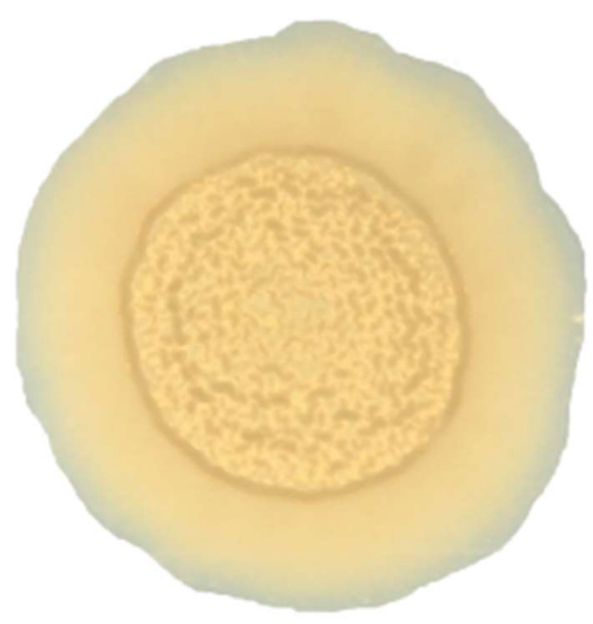

$1 \mathrm{~mm}$ 
Figure S6: Plot showing predicted number of segments vs shrinkage parameter (s) parameter using SSC for all 30 pairs of $r$ and $k$. Here we see begin to see the same predicted number of segments from different initial $\mathrm{k}$ values starting at $\mathrm{s}=6$.

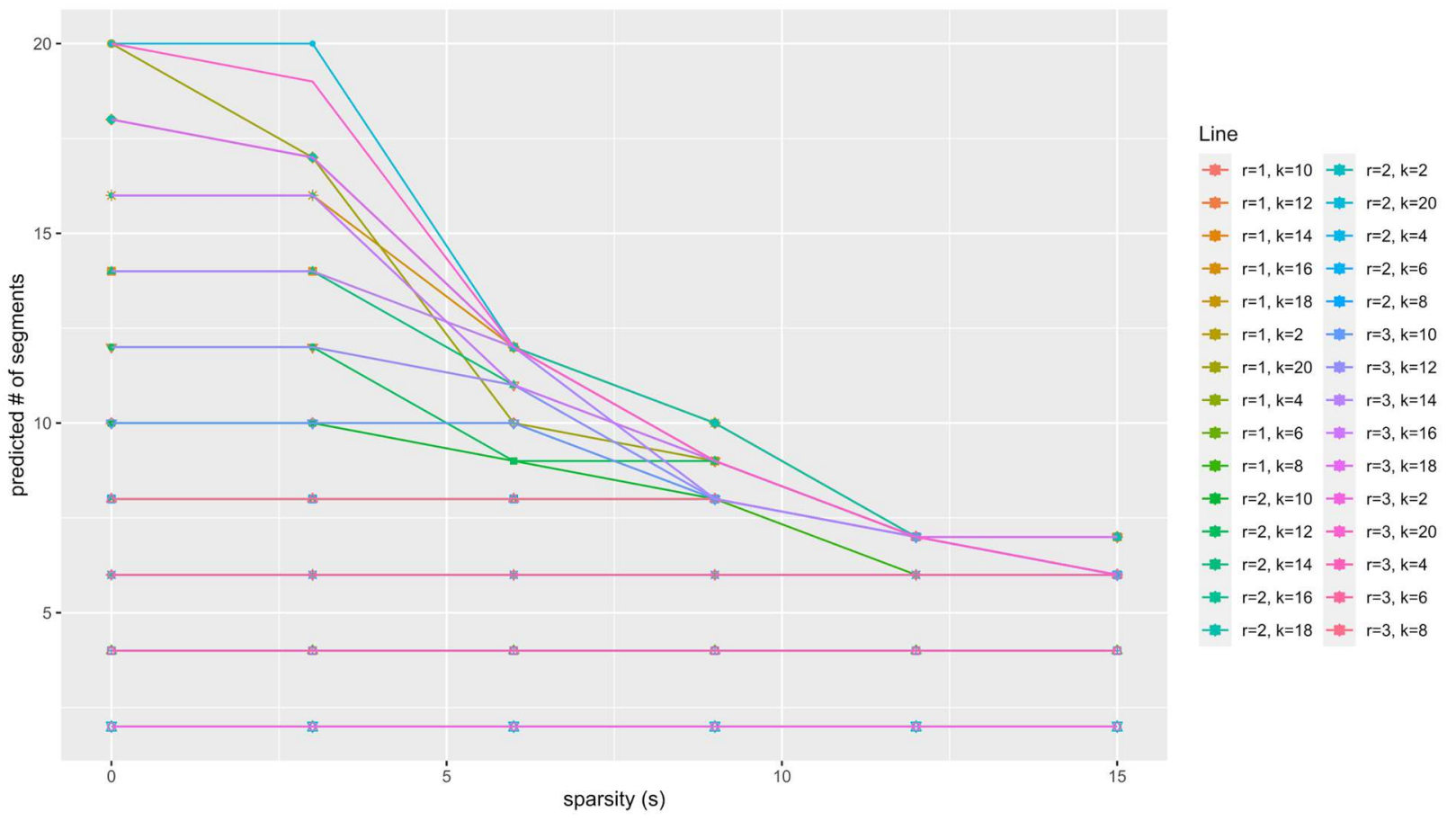


Figure S7: Plot showing weighted cardinality score vs shrinkage parameter (s) using SSC. (A) Here we see the weighted cardinality score, which is based on predicted number of segments, begin to stabilize at $s=6$. (B) Comparison of the knee found by Kneedle before and after removal of plateau data points.

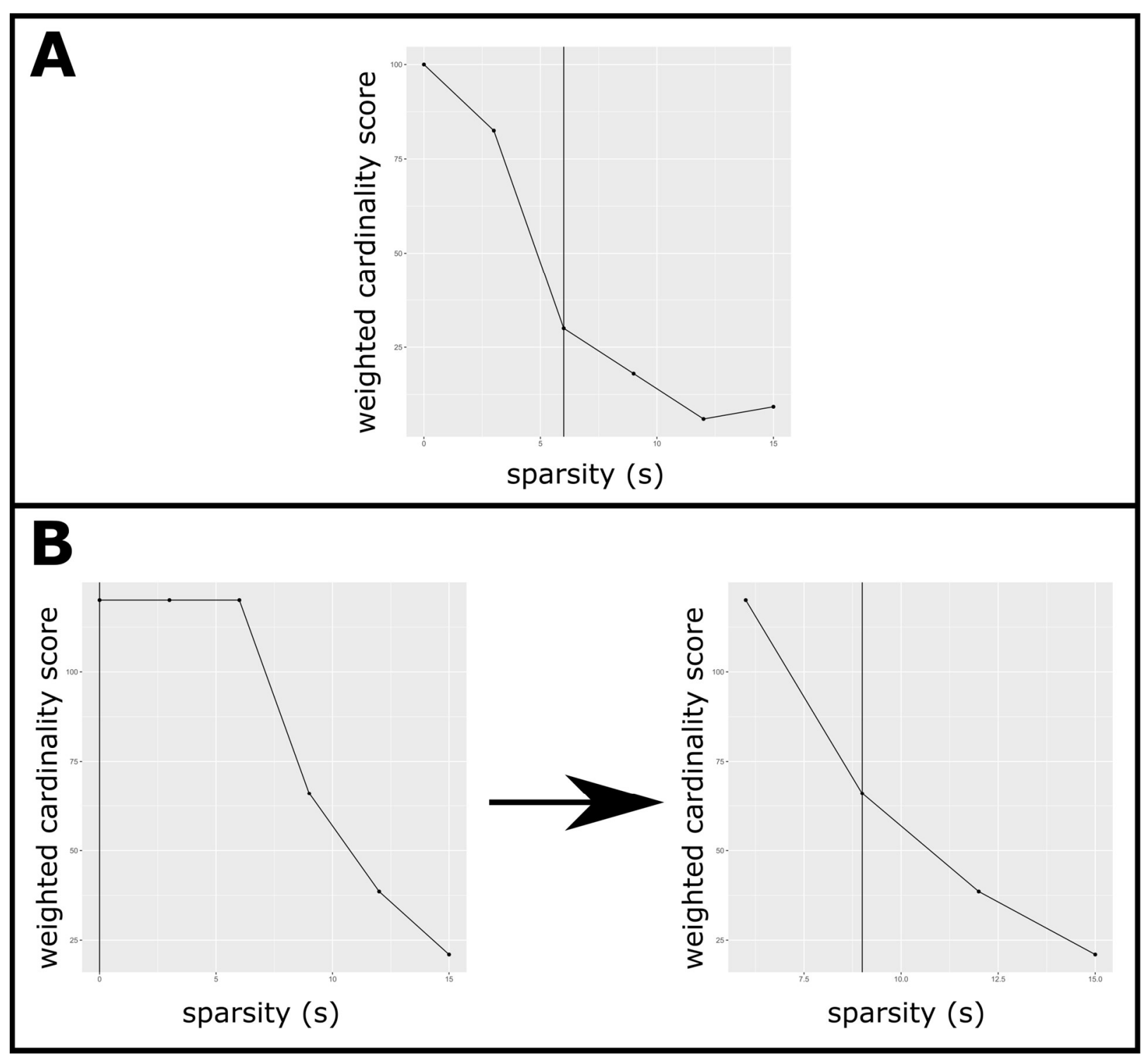


Figure S8: The effect of spatial neighborhood radius $(r)$ on unsupervised segmentation. Both images shows here come from the same data set. Colors from $A$ and $B$ do not correspond to the same segments. (A) Segmentation using spatialShrunkenCentroids with parameters: $r=1, k=8$, s12. (B) Segmentation using spatialShrunkenCentroids with parameters: $r=2, k=8, s=12$.

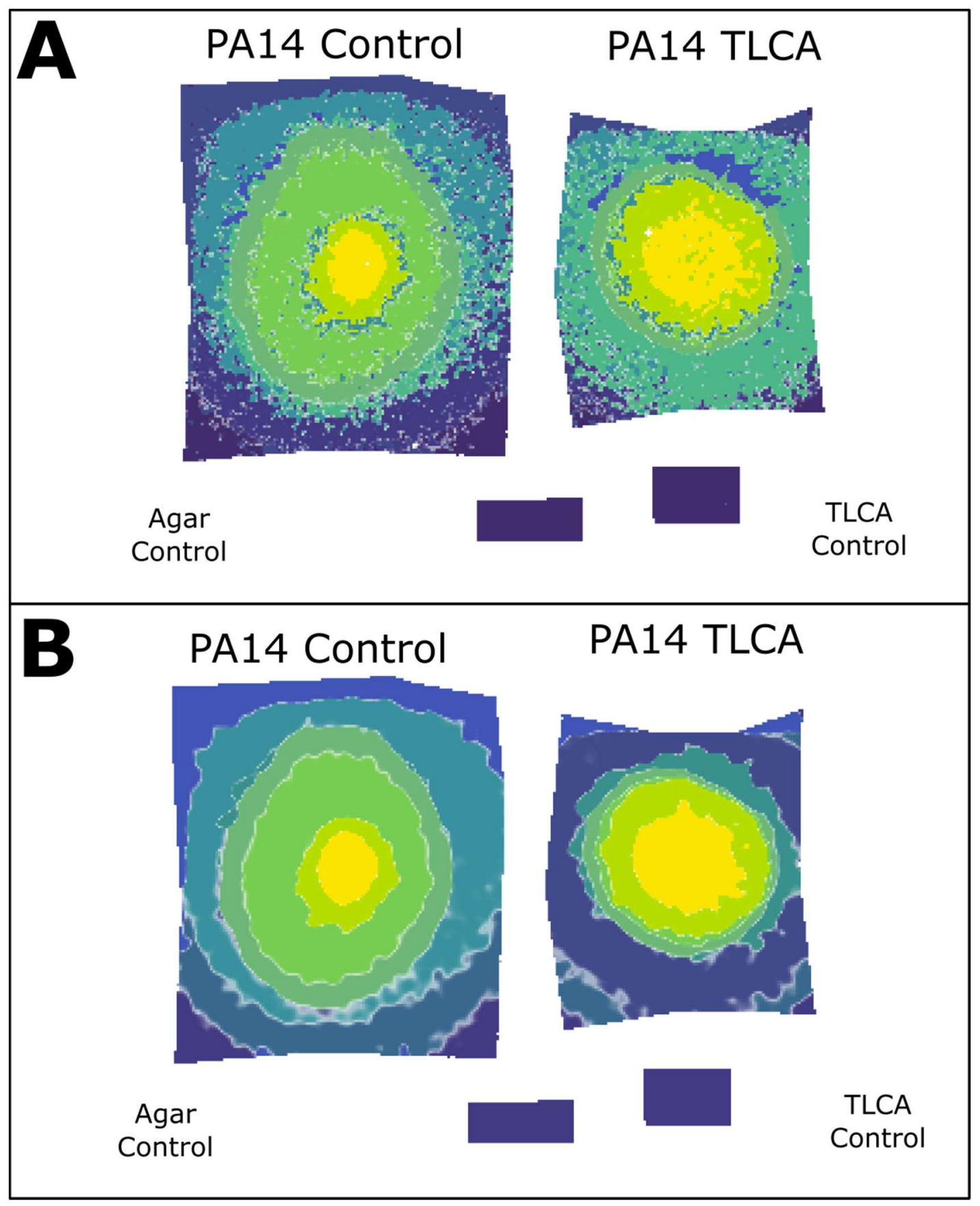


Table S1: Publications that have used Cardinal.

\begin{tabular}{|c|c|c|c|c|}
\hline Title & $\begin{array}{l}\text { Mass } \\
\text { Spectrometer(s) }\end{array}$ & Organism & Sample & Ref \\
\hline $\begin{array}{l}\text { Mapping the fly Malpighian tubule } \\
\text { lipidome by imaging mass spectrometry }\end{array}$ & MALDI-TOF & flies & lipids & 3 \\
\hline $\begin{array}{l}\text { Improved matrix coating for positive- } \\
\text { and negative-ion-mode MALDI-TOF } \\
\text { imaging of lipids in blood vessel tissues }\end{array}$ & MALDI-TOF & human & lipids & 4 \\
\hline $\begin{array}{l}\text { Mapping the triglyceride distribution in } \\
\text { NAFLD human liver by MALDI imaging } \\
\text { mass spectrometry reveals molecular } \\
\text { differences in micro and macro } \\
\text { steatosis. }\end{array}$ & $\begin{array}{l}\text { MALDI-TOF/TOF } \\
\text { (Gold-Assisted } \\
\text { Laser } \\
\text { Desorption- } \\
\text { lonization) }\end{array}$ & human & lipids & 5 \\
\hline $\begin{array}{l}\text { Metabolomic insights into the effects of } \\
\text { thyroid hormone on Rana [Lithobates] } \\
\text { catesbeiana metamorphosis using } \\
\text { whole-body Matrix Assisted Laser } \\
\text { Desorption/lonization-Mass } \\
\text { Spectrometry Imaging (MALDI-MSI). }\end{array}$ & $\begin{array}{l}\text { MALDI-Q-FT- } \\
\text { ICR }\end{array}$ & tadpole & metabolites & 6 \\
\hline $\begin{array}{l}\text { Advanced Registration and Analysis of } \\
\text { MALDI Imaging Mass Spectrometry } \\
\text { Measurements through } \\
\text { Autofluorescence Microscopy }\end{array}$ & $\begin{array}{l}\text { MALDI-TOF, } \\
\text { MALDI-FT-ICR }\end{array}$ & rat/mouse & $\begin{array}{l}\text { metabolites, } \\
\text { lipids, proteins }\end{array}$ & 7 \\
\hline $\begin{array}{l}\text { Spatial distribution of endogenous } \\
\text { tissue protease activity in gastric } \\
\text { carcinoma mapped by MALDI mass } \\
\text { spectrometry imaging }\end{array}$ & $\begin{array}{l}\text { MALDI-TOF, } \\
\text { MALDI-FT-ICR }\end{array}$ & pig/mouse & proteins & 8 \\
\hline $\begin{array}{l}\text { Single-Cell Mass Spectrometry Reveals } \\
\text { Changes in Lipid and Metabolite } \\
\text { Expression in RAW } 264.7 \text { Cells upon } \\
\text { Lipopolysaccharide Stimulation }\end{array}$ & MALDI-FT-ICR & $\begin{array}{l}\text { cell } \\
\text { culture }\end{array}$ & $\begin{array}{l}\text { metabolites, } \\
\text { lipids }\end{array}$ & 9 \\
\hline $\begin{array}{l}\text { Secondary ion mass spectrometry } \\
\text { imaging and multivariate data analysis } \\
\text { reveal co-aggregation patterns of } \\
\text { Populus trichocarpa leaf surface } \\
\text { compounds on a micrometer scale }\end{array}$ & $\begin{array}{l}\text { MALDI-TOF, } \\
\text { TOF-SIMS }\end{array}$ & plant & metabolites & 10 \\
\hline $\begin{array}{l}\text { Laser desorption/ionization MS imaging } \\
\text { of cancer kidney tissue on silver } \\
\text { nanoparticle-enhanced target }\end{array}$ & MALDI-TOF & human & metabolites & 11 \\
\hline
\end{tabular}




\begin{tabular}{|l|l|l|l|c|}
\hline $\begin{array}{l}\text { Pancreatic Cancer Surgical Resection } \\
\text { Margins: Molecular Assessment by } \\
\text { Mass Spectrometry Imaging }\end{array}$ & DESI & human & lipids & 12 \\
\hline $\begin{array}{l}\text { Three-dimensional imaging MS of lipids } \\
\text { in atherosclerotic plaques: Open-source } \\
\text { methods for reconstruction and analysis }\end{array}$ & MALDI-TOF/TOF & mouse & lipids & 13 \\
\hline $\begin{array}{l}\text { Protein biomarkers on tissue as imaged } \\
\text { via MALDI mass spectrometry: A } \\
\text { systematic approach to study the limits } \\
\text { of detection }\end{array}$ & MALDI-TOF/TOF & mouse & proteins & 14 \\
\hline $\begin{array}{l}\text { Spatio-Temporal Metabolite Profiling of } \\
\text { the Barley Germination Process by } \\
\text { MALDI MS Imaging }\end{array}$ & MALDI-TOF/TOF & plant & metabolites & 15 \\
\hline $\begin{array}{l}\text { Integrated mass spectrometry imaging } \\
\text { and omics workflows on the same } \\
\text { tissue section using grid-aided, } \\
\text { parafilm-assisted microdissection. }\end{array}$ & MALDI-Orbitrap & rat/plant/z & $\begin{array}{l}\text { metabolites, } \\
\text { lipids, proteins }\end{array}$ & 16 \\
\hline $\begin{array}{l}\text { Variations in the Abundance of Lipid } \\
\text { Biomarker lons in Mass Spectrometry } \\
\text { Images Correlate to Tissue Density }\end{array}$ & DESI & mouse & lipids & 17 \\
\hline
\end{tabular}


Table S2: Preprocessing parameters for each dataset in Cardinal. Parameters not listed here were left at their default values

\begin{tabular}{|c|c|c|c|c|c|c|c|c|}
\hline & & $\begin{array}{l}\text { WT_PA1 } \\
4 \_2016- \\
06-09\end{array}$ & $\begin{array}{l}\text { WT_PA1 } \\
4 \text { 42019- } \\
05-06\end{array}$ & $\begin{array}{l}\text { WT_PA1 } \\
4 \_2018- \\
01-12\end{array}$ & $\begin{array}{l}\text { WT_PA1 } \\
4 \_2017- \\
05-08\end{array}$ & $\begin{array}{l}\text { WT_PA1 } \\
4 \_2017- \\
09-21\end{array}$ & $\begin{array}{l}\text { Combine } \\
\text { d Data } \\
\text { Set }\end{array}$ & $\begin{array}{l}\text { PA14_Lig } \\
\text { ht- } \\
\text { Dark_Cy } \\
\text { cling }\end{array}$ \\
\hline Function & \begin{tabular}{|l|} 
Paramete \\
$\mathrm{r}$
\end{tabular} & & & & & & & \\
\hline \multirow[t]{2}{*}{$\begin{array}{l}\text { readMSI } \\
\text { Data }\end{array}$} & resolution & 200 & 200 & 200 & 200 & 200 & 200 & 200 \\
\hline & units & ppm & ppm & ppm & ppm & ppm & ppm & ppm \\
\hline normalize & \begin{tabular}{|l|} 
Algorithm \\
/Method
\end{tabular} & RMS & RMS & RMS & RMS & RMS & RMS & TIC \\
\hline $\begin{array}{l}\text { smoothSi } \\
\text { gnal }\end{array}$ & \begin{tabular}{|l|} 
Algorithm \\
/Method
\end{tabular} & $\begin{array}{l}\text { Savitzky- } \\
\text { Golay }\end{array}$ & $\begin{array}{l}\text { Savitzky- } \\
\text { Golay }\end{array}$ & $\begin{array}{l}\text { Savitzky- } \\
\text { Golay }\end{array}$ & $\begin{array}{l}\text { Savitzky- } \\
\text { Golay }\end{array}$ & $\begin{array}{l}\text { Savitzky- } \\
\text { Golay }\end{array}$ & $\begin{array}{l}\text { Savitzky- } \\
\text { Golay }\end{array}$ & \begin{tabular}{|l|} 
Savitzky- \\
Golay
\end{tabular} \\
\hline $\begin{array}{l}\text { reduceBa } \\
\text { seline }\end{array}$ & $\begin{array}{l}\text { Algorithm } \\
\text { /Method }\end{array}$ & $\begin{array}{l}\text { interpolat } \\
\text { ed } \\
\text { median }\end{array}$ & $\begin{array}{l}\text { interpolat } \\
\text { ed } \\
\text { median }\end{array}$ & $\begin{array}{l}\text { interpolat } \\
\text { ed } \\
\text { median }\end{array}$ & $\begin{array}{l}\text { interpolat } \\
\text { ed } \\
\text { median }\end{array}$ & $\begin{array}{l}\text { interpolat } \\
\text { ed } \\
\text { median }\end{array}$ & $\begin{array}{l}\text { interpolat } \\
\text { ed } \\
\text { median }\end{array}$ & $\begin{array}{l}\text { interpolat } \\
\text { ed } \\
\text { median }\end{array}$ \\
\hline \multirow[t]{2}{*}{ peakPick } & \begin{tabular}{|l|} 
Algorithm \\
/Method
\end{tabular} & simple & simple & simple & simple & simple & simple & simple \\
\hline & \begin{tabular}{|l|} 
Signal-to- \\
Noise \\
Ratio
\end{tabular} & 4 & 4 & 4 & 4 & 4 & 4 & 4 \\
\hline $\begin{array}{l}\text { peakAlig } \\
n\end{array}$ & $\begin{array}{l}\text { Toleranc } \\
\mathrm{e}\end{array}$ & $\pm \mathrm{m} / \mathrm{z} \quad 0.2$ & $\pm m / z 0.2$ & $\pm \mathrm{m} / \mathrm{z} 0.2$ & $\pm \mathrm{m} / \mathrm{z} 0.2$ & $\pm \mathrm{m} / \mathrm{z} \quad 0.2$ & $\begin{array}{l}\text { NA } \\
\text { (default) }\end{array}$ & $\pm m / z 0.2$ \\
\hline $\begin{array}{l}\text { peakFilte } \\
r\end{array}$ & \begin{tabular}{|l|} 
Minimum \\
Frequenc \\
y
\end{tabular} & 0.05 & 0.05 & 0.05 & 0.05 & 0.05 & 0.05 & 0.05 \\
\hline
\end{tabular}

Table S3: Optimized SpatialShrunkenCentroid parameters for unsupervised segmentation

\begin{tabular}{|l|l|l|l|l|l|l|}
\hline & $\begin{array}{l}\text { PA14_2016 } \\
-06-09\end{array}$ & $\begin{array}{l}\text { PA14_2018 } \\
-01-12\end{array}$ & $\begin{array}{l}\text { PA14_2019 } \\
-05-06\end{array}$ & $\begin{array}{l}\text { PA14_2017 } \\
-5-08\end{array}$ & $\begin{array}{l}\text { PA14_2017 } \\
-09-21\end{array}$ & $\begin{array}{l}\text { PA14_Light- } \\
\text { Dark_Cycling }\end{array}$ \\
\hline $\mathrm{r}$ & 1 & 1 & 2 & 2 & 1 & 3 \\
\hline $\mathrm{k}$ & 18 & 20 & 20 & 14 & 12 & 8 \\
\hline $\mathrm{s}$ & 0 & 6 & 6 & 6 & 9 & 3 \\
\hline
\end{tabular}


(1) Bemis, K. D.; Harry, A.; Eberlin, L. S.; Ferreira, C. R.; van de Ven, S. M.; Mallick, P.; Stolowitz, M.; Vitek, O. Probabilistic Segmentation of Mass Spectrometry (MS) Images Helps Select Important lons and Characterize Confidence in the Resulting Segments. Molecular \& Cellular Proteomics. 2016, pp 1761-1772.

https://doi.org/10.1074/mcp.0115.053918.

(2) Satopaa, V.; Albrecht, J.; Irwin, D.; Raghavan, B. Finding a“ Kneedle" in a Haystack: Detecting Knee Points in System Behavior. In 2011 31st international conference on distributed computing systems workshops; IEEE, 2011; pp 166-171.

(3) Yang, E.; Gamberi, C.; Chaurand, P. Mapping the Fly Malpighian Tubule Lipidome by Imaging Mass Spectrometry. J. Mass Spectrom. 2019, 54 (6), 557-566.

(4) Meisenbichler, C.; Doppler, C.; Bernhard, D.; Müller, T. Improved Matrix Coating for Positive- and Negative-lon-Mode MALDI-TOF Imaging of Lipids in Blood Vessel Tissues.

Anal. Bioanal. Chem. 2019, 411 (15), 3221-3227.

(5) Alamri, H.; Patterson, N. H.; Yang, E.; Zoroquiain, P.; Lazaris, A.; Chaurand, P.; Metrakos, $P$. Mapping the Triglyceride Distribution in NAFLD Human Liver by MALDI Imaging Mass Spectrometry Reveals Molecular Differences in Micro and Macro Steatosis. Anal. Bioanal. Chem. 2019, 411 (4), 885-894.

(6) Luehr, T. C.; Koide, E. M.; Wang, X.; Han, J.; Borchers, C. H.; Helbing, C. C. Metabolomic Insights into the Effects of Thyroid Hormone on Rana [Lithobates] Catesbeiana Metamorphosis Using Whole-Body Matrix Assisted Laser Desorption/lonization-Mass Spectrometry Imaging (MALDI-MSI). Gen. Comp. Endocrinol. 2018, 265, 237-245.

(7) Patterson, N. H.; Tuck, M.; Van de Plas, R.; Caprioli, R. M. Advanced Registration and Analysis of MALDI Imaging Mass Spectrometry Measurements through Autofluorescence Microscopy. Anal. Chem. 2018, 90 (21), 12395-12403.

(8) Erich, K.; Reinle, K.; Müller, T.; Munteanu, B.; Sammour, D. A.; Hinsenkamp, I.; Gutting, T.; Burgermeister, E.; Findeisen, P.; Ebert, M. P.; et al. Spatial Distribution of Endogenous Tissue Protease Activity in Gastric Carcinoma Mapped by MALDI Mass Spectrometry Imaging. Mol. Cell. Proteomics 2019, 18 (1), 151-161.

(9) Yang, B.; Patterson, N. H.; Tsui, T.; Caprioli, R. M.; Norris, J. L. Single-Cell Mass Spectrometry Reveals Changes in Lipid and Metabolite Expression in RAW 264.7 Cells upon Lipopolysaccharide Stimulation. J. Am. Soc. Mass Spectrom. 2018, 29 (5), 10121020.

(10) Kulkarni, P.; Dost, M.; Bulut, Ö. D.; Welle, A.; Böcker, S.; Boland, W.; Svatoš, A. Secondary Ion Mass Spectrometry Imaging and Multivariate Data Analysis Reveal CoAggregation Patterns of Populus Trichocarpa Leaf Surface Compounds on a Micrometer Scale. Plant J. 2018, 93 (1), 193-206.

(11) Arendowski, A.; Nizioł, J.; Ossoliński, K.; Ossolińska, A.; Ossoliński, T.; Dobrowolski, Z.; Ruman, T. Laser Desorption/ionization MS Imaging of Cancer Kidney Tissue on Silver Nanoparticle-Enhanced Target. Bioanalysis 2018, 10 (2), 83-94.

(12) Eberlin, L. S.; Margulis, K.; Planell-Mendez, I.; Zare, R. N.; Tibshirani, R.; Longacre, T. A.; Jalali, M.; Norton, J. A.; Poultsides, G. A. Pancreatic Cancer Surgical Resection Margins: Molecular Assessment by Mass Spectrometry Imaging. PLoS Med. 2016, 13 (8), e1002108.

(13) Patterson, N. H.; Doonan, R. J.; Daskalopoulou, S. S.; Dufresne, M.; Lenglet, S.; Montecucco, F.; Thomas, A.; Chaurand, P. Three-Dimensional Imaging MS of Lipids in Atherosclerotic Plaques: Open-Source Methods for Reconstruction and Analysis. Proteomics 2016, 16 (11-12), 1642-1651.

(14) van de Ven, S. M. W. Y.; Bemis, K. D.; Lau, K.; Adusumilli, R.; Kota, U.; Stolowitz, M.; Vitek, O.; Mallick, P.; Gambhir, S. S. Protein Biomarkers on Tissue as Imaged via MALDI Mass Spectrometry: A Systematic Approach to Study the Limits of Detection. Proteomics 2016, 16 (11-12), 1660-1669. 
(15) Gorzolka, K.; Kölling, J.; Nattkemper, T. W.; Niehaus, K. Spatio-Temporal Metabolite Profiling of the Barley Germination Process by MALDI MS Imaging. PLoS One 2016, 11 (3), e0150208.

(16) Quanico, J.; Franck, J.; Wisztorski, M.; Salzet, M.; Fournier, I. Integrated Mass Spectrometry Imaging and Omics Workflows on the Same Tissue Section Using GridAided, Parafilm-Assisted Microdissection. Biochim. Biophys. Acta Gen. Subj. 2017, 1861 (7), 1702-1714.

(17) Bilkey, J.; Tata, A.; McKee, T. D.; Porcari, A. M.; Bluemke, E.; Woolman, M.; Ventura, M.; Eberlin, M. N.; Zarrine-Afsar, A. Variations in the Abundance of Lipid Biomarker lons in Mass Spectrometry Images Correlate to Tissue Density. Anal. Chem. 2016, 88 (24), 12099-12107. 